\title{
Global satellite monitoring of climate-induced vegetation disturbances
}

\author{
Nate G. McDowell ${ }^{1}$, Nicholas C. Coops ${ }^{2}$, Pieter S.A. Beck ${ }^{3}$, Jeffrey Q. Chambers ${ }^{4}$, \\ Chandana Gangodagamage ${ }^{1}$, Jeffrey A. Hicke ${ }^{5}$, Cho-ying Huang ${ }^{6}$, Robert Kennedy ${ }^{7}$, \\ Dan J. Krofcheck ${ }^{8}$, Marcy Litvak ${ }^{8}$, Arjan J.H. Meddens ${ }^{5}$, Jordan Muss ${ }^{1}$, \\ Robinson Negrón-Juarez ${ }^{4}$, Changhui Peng ${ }^{9}$, Amanda M. Schwantes ${ }^{10}$, \\ Jennifer J. Swenson ${ }^{10}$, Louis J. Vernon ${ }^{1}$, A. Park Williams ${ }^{11}$, Chonggang $\mathrm{Xu}^{1}$, \\ Maosheng Zhao ${ }^{12}$, Steve W. Running ${ }^{13}$, and Craig D. Allen ${ }^{14}$
}

\footnotetext{
${ }^{1}$ Los Alamos National Lab, Earth and Environmental Sciences Division, Los Alamos, NM 87545, USA

${ }^{2}$ Faculty of Forestry, University of British Columbia, 2424 Main Mall, Vancouver, BC V6T1Z4, Canada

${ }^{3}$ Institute for Environment and Sustainability, Joint Research Centre, European Commission, Via E. Fermi 2749,21027 Ispra (VA), Italy

${ }^{4}$ Lawrence Berkeley National Lab, Earth Science Division, Berkeley, CA 94720, USA

${ }^{5}$ University of Idaho, Department of Geography, Moscow, ID 83844-3021, USA

${ }^{6}$ Department of Geography, National Taiwan University, Taipei 10617, Taiwan

${ }^{7}$ Department of Earth and Environment, Boston University, Boston, MA, 02215, USA

${ }^{8}$ Biology Department, University of New Mexico, Albuquerque, NM 87131-0001, USA

${ }^{9}$ Center of CEF/ESCER, Department of Biological Science, University of Quebec at Montreal, Montreal H3C 3P8, Canada and State Key Laboratory of Soil Erosion and Dryland Farming on the Loess Plateau, Northwest A\&F University, Yangling, 712100, China

${ }^{10}$ Nicholas School of the Environment, Duke University, Durham, NC 27708, USA

${ }^{11}$ Lamont-Doherty Earth Observatory, Columbia University, Palisades, NY 10964, USA

${ }^{12}$ Department of Geographical Sciences, University of Maryland, College Park, MD 20742, USA

${ }^{13}$ Department of Ecosystem and Conservation Sciences, University of Montana, MT 59812, USA

${ }^{14}$ United States Geological Survey, Fort Collins Science Center, Jemez Mountain Field Station, Los Alamos, NM 87544, USA
}

Terrestrial disturbances are accelerating globally, but their full impact is not quantified because we lack an adequate monitoring system. Remote sensing offers a means to quantify the frequency and extent of disturbances globally. Here, we review the current application of remote sensing to this problem and offer a framework for more systematic analysis in the future. We recommend that any proposed monitoring system should not only detect disturbances, but also be able to: identify the proximate cause(s); integrate a range of spatial scales; and, ideally, incorporate process models to explain the observed patterns and predicted trends in the future. Significant remaining challenges are tied to the ecology of disturbances. To meet these challenges, more effort is required to incorporate ecological principles and understanding into the assessments of disturbance worldwide.

Global disturbance detection

Changing climate has been linked to an increased rate of vegetation disturbances and mortality, promoting major

Corresponding author: McDowell, N.G. (mcdowell@lanl.gov).

Keywords: climate change; die-off; drought; forests; landscape; mortality; satellite.

$1360-1385 /$

(c) 2014 Elsevier Ltd. All rights reserved. http://dx.doi.org/10.1016/j.tplants.2014.10.008 changes in the condition of forest and woodland ecosystems [1-5]. These disturbance events have been observed across all biomes and plant functional types on all vegetated continents [6,7]. These findings have led to the development of a hypothesis that climate warming is associated with increased physiological stress that is causing elevated mortality of tree and woodland species globally [6,7]. In addition to the well-demonstrated links to disturbance changes on the carbon cycle [8-11], disturbed ecosystems also have impacts on human society (e.g., [12]).

Management options for mitigating and adapting to disturbances are easier a priori rather than $a$ posteriori [13], but we must first understand when, where, why, and at what scale these disturbances occur. To date, there is no consistent map of past disturbance events and their causes at the global scale. Multidecadal observations of disturbance events and their associated mortality are limited to sparse plot studies; thus, we cannot test the hypothesis that disturbance events are increasing in size and number $[6,7]$. It is even more challenging to document disturbance causes and impacts.

Disturbance information is also needed to constrain and evaluate dynamic global vegetation models (DGVMs). Disturbance processes are incorporated into DGVMs as simple approximations (e.g., [14-17]). Among the greatest limitations to disturbance simulation is the paucity of global 
disturbance data to inform and evaluate the models [18]. It is critical that we provide this information so that DGVMs, which are essential components of both impacts and climate prediction within earth system models, can be improved to capture disturbance processes.

Remote-sensing data volumes and computational methods have recently led to rapid advances in capability that promise to substantially improve understanding of disturbances. We argue in this review that such advances be accompanied by improved integration with ecological understanding, modeling, and direct observations. To this end, we propose an idealized framework (Figure 1A) for a global disturbance detection and attribution system for hypotheses testing across a range of disturbance types and scales (Figure 1B). We review the state of remote sensing of vegetation disturbances, highlight the challenges that remain, and examine the evidence supporting our proposed global disturbance monitoring system. We present both original and published data to support our analytic framework. A dominant property of this review is that ecological understanding of disturbance and succession processes has a critical role in the interpretation of remotely sensed imagery of disturbance.

\section{Defining and observing disturbance}

No single definition of disturbance satisfies all scientific and societal questions; thus, our definition must be explicit

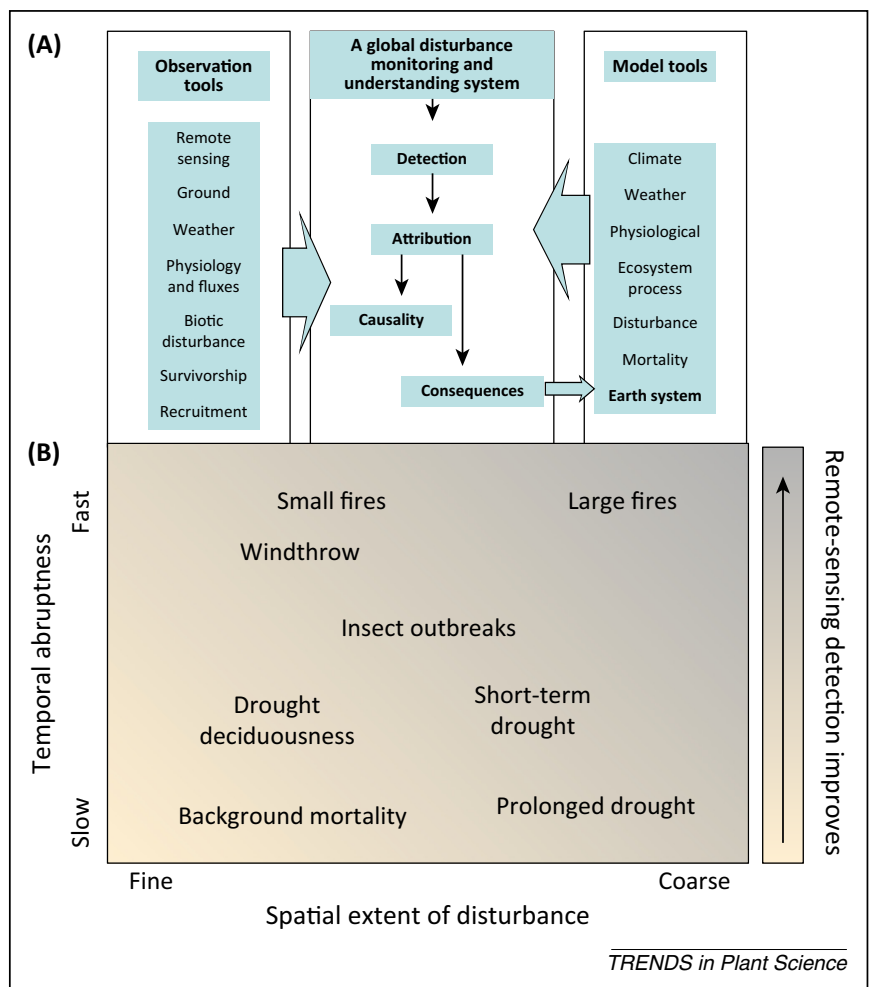

Figure 1. A global disturbance-monitoring framework. (A) Our proposed global disturbance monitoring and understanding framework includes not only remote sensing as the critical observational tool, but also multiple other observational and modeling tools to understand attribution, causation, and consequences. The tools refer specifically to the scale and process of interest; for example, ground tools for assessing disturbance, meteorological stations to assess weather, and so on (B) Quantifying terrestrial disturbances with remotely sensed imagery is inherently dependent on the spatial resolution of the images and frequency of data collection relative to the extent of the disturbances and the speed of disturbance occurrence and recovery. and simple. For the purposes of defining the working requirements of a globally comprehensive disturbance monitoring system, we propose that disturbances are any processes that lead to the significant removal of canopy leaf area and live biomass. By this definition, mortality of entire individuals (see [18] for mortality definitions) is not required for a disturbance; rather, only dieback of the canopy at an anomalous rate compared with slower and smaller dieback associated with competition and interannual climate variability [19].

Disturbance events occur at a range of spatial and temporal scales and include wind (including hurricanes), fire, drought, floods, insects and pathogens, harvest, ice, hail, avalanches, and landslides (and harvests; which is not a focus of this review). These can occur instantaneously or over years. Disturbance detection is often based on changes in foliage, because this is the most vulnerable biotic component of terrestrial ecosystems observable from optical observations [20-22]. Although we have a wealth of knowledge, we still do not have sufficient understanding of disturbances to forecast their occurrence and impacts under changing climate conditions [23,24].

\section{An example of the challenges and potential of remotely sensed disturbances}

Remote sensing has been used for detection of disturbance since satellite-based optical technologies first became available [25]. The combination of a range of spatial and temporal signatures of disturbance, coupled with the range of spatial and temporal detection capability of the various satellite-based instruments, leads to a range of trade-offs that must be balanced to maximize detection accuracy. Among many disturbance indices, the Moderate Resolution Imaging Spectrometer (MODIS) Global Disturbance Index (MGDI), using information on vegetation greenness and surface temperature, allows global monitoring of disturbances at an annual time-step (e.g., [26,27]; Figure 2A). MGDI is principally designed for global coverage with low spatial resolution and a limited temporal history (500 m from 2005 to 2012 in Figure 2A), which is generally too coarse for monitoring localized disturbances [28].

Imagery at finer spatial scales (optical: $30-80 \mathrm{~m}$; thermal: $60-120 \mathrm{~m}$ ) has been available since the launch of Landsat-1 in 1972 [25] and allows for more detailed analysis of disturbances. Historically, high costs and limited computing power resulted in a single-scene analysis strategy; however, recent changes resulting in an open and free data access policy have greatly increased the amount of Landsat imagery being analyzed. This resulted in the first global assessment of forest-cover change at a $30-\mathrm{m}$ spatial resolution from 2000 to 2012 ([29]; Figure 2B), utilizing new processing methods and interface development in a cloud computer platform.

Differences between the 500-m (MGDI) and 30-m resolution maps (contrast Figure 2A and 2B) are a function of application domain, temporal frequency, and spatial resolution. For example, the algorithms differ in their use of vegetation and biophysical indices. Furthermore, the 500-m coarse resolution of MODIS misses disturbances occurring at the finer scales [30]; however, MGDI classifies 


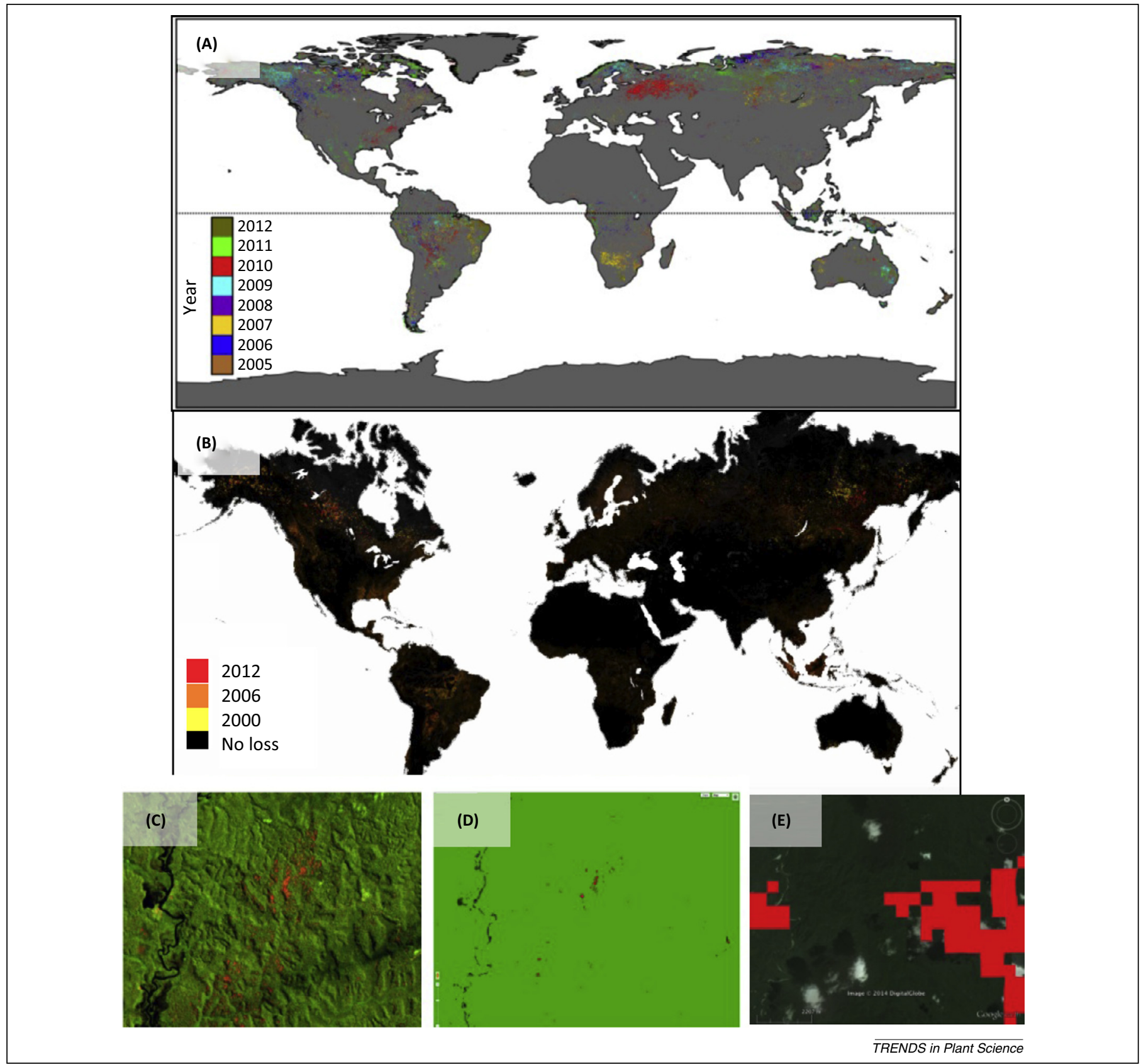

Figure 2. Examples of global monitoring capabilities. (A) The Moderate Resolution Imaging Spectrometer (MODIS) Global Disturbance Index (MGDI; 500 m), and (B) the Landsat-based global forest change detections $(30 \mathrm{~m})$. The approximate year of detection for each system is provided within each legend. Each of these maps represents major breakthroughs for the time period. In (B), Hansen et al. [29] provided the first user-friendly, interactive web-based tool that allowed examination of the global patterns of forest loss and gain since year 2000 via 30-m resolution Landsat analysis. (C-E) show a zoomed-in landscape near Manaus, Brazil. The ground-referenced data set (C) is a

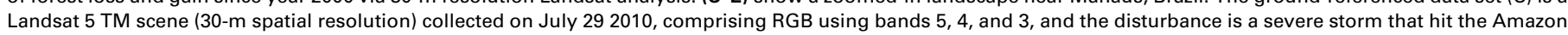
basin on January 16-18 2005 [51]. Forest loss from [29] is shown in (D), and (E) is the MGDI. (C,D) both show results from 30-m resolution imagery (Landsat); however, (C)

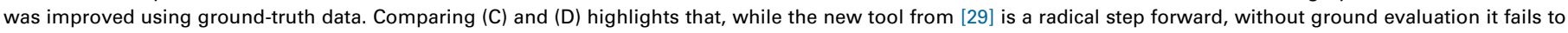
pick up mortality at finer scales that may be a dominant component of global mortality. Nonetheless, the improvement of using 30 -m resolution imagery is clear when comparing $(C, D)$ to $M G D I(E)$, which has a resolution of $500 \mathrm{~m}$.

disturbances for all woody ecosystems, including shrublands and savannas [27], whereas the Landsat product ([29]; Figure 2B) only included disturbances for vegetation with height $\geq 5 \mathrm{~m}$. In comparison to the nearly daily MODIS overpass, the ca. 16-day overpass of Landsat reduces the likelihood of obtaining cloud-free observations [31]. As demonstrated in Figure 2C-E, and discussed in detail in the section Spatial detection considerations, spatial resolution (30 $\mathrm{m}$ versus $500 \mathrm{~m}$ ) may be another critical driver of the detection differences. In sum, recent advances in data distribution and processing illustrate the ability to analyze fine spatial resolution $(30 \mathrm{~m})$ remotely sensed data for global scale monitoring.

Although not yet global in application, $\sim 1 \mathrm{~m}$ resolution optical imagery is valuable for detailed assessments of vegetation characteristics because it can resolve individual tree canopies (e.g., [32,33]). Microwave and other nonoptical remote-sensing techniques, while not the main object 
of this review, are covered under the section on dense forest canopies below.

\section{Creating a framework for global detection of disturbances and their causes}

Given the large recent advances and the range of techniques available, coupled with the increasing frequency of disturbances, it seems logical that remote sensing is poised to make large and important breakthroughs in disturbance monitoring. For maximum benefit to scientists, such breakthroughs would benefit from not only improving detection, but also enabling one to determine the disturbance type, its cause, and its consequences. We offer a framework for analyzing global disturbances that has four major components (Figure 1A): (i) detection of the disturbance event in time and space; (ii) attribution of the type of event(s); (iii) causality, or understanding the mechanism of disturbance; and (iv) information regarding effects and consequences of the disturbance(s). Therefore, the ideal framework is a combination of observations, statistics, and modeling, with detection and attribution being observation focused, and causality and consequences more derived from empirical or process model analysis. This framework depends on intimate ecological knowledge of the system, particularly when the scale is global. Developments of global systems that contain parts of this idealized framework are of proven value (e.g., $[26,29])$ as stepping-stones to the proposed framework. The opportunities, trade-offs, and pitfalls associated with this framework, in particular, the remote-sensing technologies, are provided in the following sections.

\section{Detection of disturbance}

Detection of disturbance from optical remote sensing can be based on spectral shifts caused by changes in pigment and foliage structure or through complete loss of pigment, defoliation, and mortality. Additionally, vegetation change associated with disturbance may be accompanied by other distinct reflectance changes, such as burnt matter, bare soil, or a reorganization of the vegetation vertically or horizontally in space (e.g., [34]). Although most detection of disturbances has historically been achieved with passive systems, increasing availability and ease of use of active sensor systems, such as radar [35] or Light Detection and Ranging (LIDAR [36]), allows added discrimination to discern changes in forest structure. Although this review is focused on passive optical systems, the ecological prerequisites apply to all remote-sensing systems.

\section{Spectral detection considerations}

Myriad studies have demonstrated that disturbances can be recognized using different spectral bands. Particularly relevant sections of the spectrum for disturbance assessment are: (i) visible $(0.4-0.7 \mu \mathrm{m})$ and near-infrared $(0.7-$ $1.3 \mu \mathrm{m})$ regions sensitive to chlorophyll absorption, cellular scattering, and leaf area [which can be cross-compared, such as through the Normalized Difference Vegetation Index (NDVI)]; (ii) short-wave infrared $(1.3-2.5 \mu \mathrm{m})$ that is sensitive to soil, nonphotosynthetic vegetation (NPV; wood and surface litter), water content, and burnt vegetation; and (iii) thermal regions $(8-14 \mu \mathrm{m})$ where vegetation water stress or a reduction in vegetation cover can lead to an increase in surface temperature [37-39]. Many approaches have been developed to leverage different parts of the electromagnetic spectrum for disturbance detection through algebraic indices (e.g., NDVI) or rotations, such as the Tasseled Cap transformation [40-42], which produces brightness, greenness, and wetness from Landsat. Other indices have been developed for canopy moisture detection (e.g., Vegetation Drought Response Index [43]) and temperature stress (e.g., Temperature Condition Index [44]) for the AVHRR sensor. Each region of the spectrum can be used complementarily for vegetation disturbance detection [45].

Dense montane and tropical forested areas present a different set of challenges in disturbance detection. A high frequency of cloud cover often limits comparison of imagery over short periods, whereas more frequent coverage can limit spatial resolution [37]. Biomass changes are harder to detect at higher canopy densities because the ability to characterize foliage levels with multispectral measurements diminishes as leaf area increases [46]. Satellite microwave backscatter provides a partial solution to this problem due to its capture of vegetation structure and water content, allowing assessment of biomass changes in dense canopies (e.g., [35]). Likewise, LIDAR enables assessments of forest biomass change in dense canopies (e.g., [47]). Expansion of these techniques and their integration with optical techniques may allow regional to global assessments of disturbances in dense forests (e.g., [48]).

\section{Spatial detection considerations}

Our proposed monitoring framework is dependent on the spatial scale of disturbances and imagery (Figure 1B). As a result, the patterns that are discernable are dependent on the target of interest (e.g., single tree versus stand disturbances) and the spatial, spectral, and temporal characteristics of the disturbance [49,50]. Beyond these characteristics, the inherent limitations of the platforms and their sensors are paramount in documenting detection lower limits; that is, an awareness of what level of disturbance yields false-negative results [50].

Disturbances that are diffuse, heterogeneous over the landscape, and occur slowly are more difficult to detect with remote sensing compared with disturbances of large numbers of trees, such as stand-replacing infestation or fire (Figure 1B [22]). As a result, the accuracy of a global detection and attribution system varies with disturbance type relative to the scale of the imagery (e.g., high frequency at $250-1100 \mathrm{~m}$ versus annual images at $<0.5-4 \mathrm{~m}$ ). The challenge of detecting disturbances that occur at the scale of individual plants is highlighted in Figure 2C-E, which demonstrates that wind events that disturb areas less than $900 \mathrm{~m}^{2}[51,52]$ are not readily detected without extensive ground evaluation. In Figure 2C-E, we see that Landsat is more accurate than MODIS for spatial detection; however, if high precision is required for a given site, then even the 30-m Landsat product is insufficient and more ground reference information is required to ensure accurate disturbance mapping. This analysis does not consider temporal limitations of Landsat relative to MODIS. The level of canopy loss required for accurate detection varies with the 
ecosystem of study, the type of disturbance, and level of accuracy deemed necessary by the scientist(s) or policy makers.

\section{Temporal detection considerations}

Significant challenges arise when considering the temporal dynamics of disturbances. Slow-acting disturbances, such as prolonged drought, are difficult to detect when compared with abrupt events, such as wildfire, unless sufficient repeat imagery is available to distinguish disturbances from other temporal change. Many disturbances are followed by rapid regrowth of surviving or colonizing plants (i.e., succession), quickly obscuring the spectral condition needed to detect disturbance. Thus, detection requires measurement at timescales appropriate for the disturbance process of interest [53-55].

We illustrate the challenge created by vegetation regrowth following disturbance using an example from a woodland following drought-induced mortality. Piñon pine (Pinus edulis) mortality occurred near the end of a prolonged drought throughout much of southwestern USA in 2002-2003 [1], causing remotely sensed NDVI to decline as leaf area was lost to overstory mortality (Figure 3 and supplementary material online). However, within 12 months, high leaf nitrogen and photosynthetic rates of the understory caused NDVI to approach values observed before the disturbance, which could lead to a false interpretation of recovered overstory vegetation (Figure 3 ). Optical approaches to isolate overstory from understory dynamics lay in using high spatial resolution imagery, spectral mixture analysis, and time-series analysis.

High spatial resolution imagery, such as 1-m ortho photography, provides an option that allows detection of even minor disturbances (e.g., the top row in Figure S1 in the supplementary material online). At the 1-m scale, the influence of the understory and mixed coverage within pixels is minimized, and individual tree crowns can be delineated $[32,33,50]$. With gains in computing power and availability of high spatial resolution data, regional

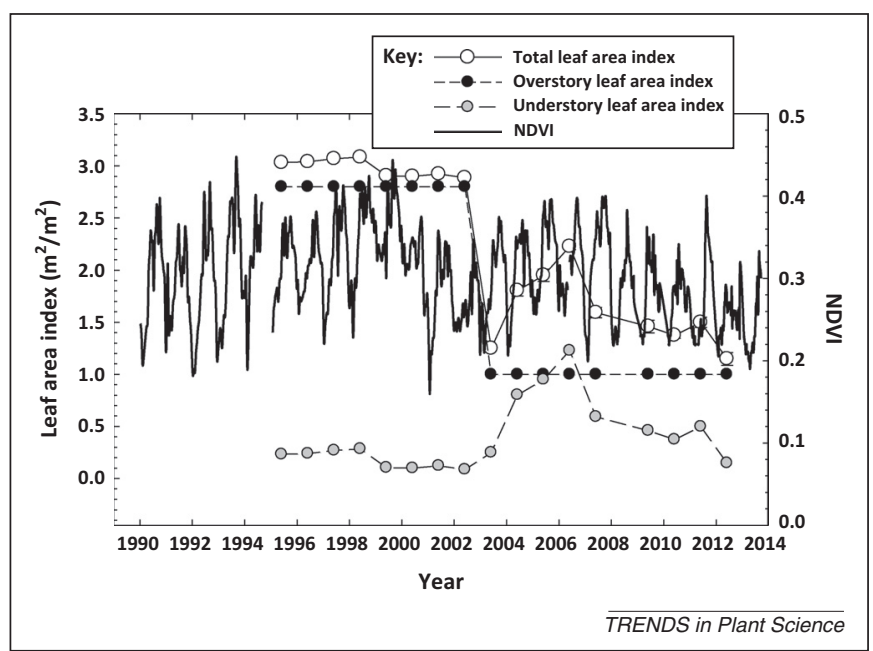

Figure 3. The challenge of accurate monitoring of disturbances. Ground measurements of leaf area index at a site in northern New Mexico, and Landsatbased Normalized Difference Vegetation Index (NDVI) for the same location. Juniper trees survived whereas piñon pine trees died in 2002-2003, after which the understory vegetation drove variation in NDVI. disturbance maps will likely be created at increasingly finer scales.

Remote-sensing approaches that 'unmix' pixels, such as spectral mixture analysis (SMA), can also detect widespread but diffuse disturbances (Figure S2 in the supplementary material online). We use a case study to highlight the value of the SMA technique. Aspen forests have recently experienced loss of aboveground biomass in western North America [56]. In this case, it is not the greening up of the understory after mortality that confounds detection of aboveground losses, but pre-existence of a green understory (Figure S2A in the supplementary material online) that results in the Enhanced Vegetation Index revealing only slight differences between dying and healthy stands (Figure S2B in the supplementary material online). The impact of understory greenness on remote-sensing monitoring can be mitigated using SMA [57], because it can quantify top-layer canopy mortality as an increase in NPV (branches) that obstruct the green understory. Figure S2C in the supplementary material online shows a hindcast of SMA-derived Landsat green and nongreen vegetation cover in healthy and dying forests, allowing clear partitioning of dying and surviving canopies [58].

An additional temporal challenge can occur for chronic but subtle disturbances, such as those associated with increasing temperatures [59]. Such disturbances expand slowly over space and time. If the spatial resolution of the remotely sensed imagery is larger than individual plants, the accumulating mortality manifests as a slowly deteriorating signal $[50,60,61]$. For example, time-series analysis of Landsat imagery coupled to limited ground-truth data can distinguish various types of disturbance that affect high-elevation forests in New Mexico (Figure S3 in the supplementary material online). In this case, fire shows an abrupt signal loss, Picea engelmannii mortality shows a moderately abrupt signal decline, and mortality of mixed coniferous forests exhibits the least abrupt, but most continuous signal decline. Notably, these trends can also be used for attribution of causes (see below).

\section{Disturbance classification}

Distinguishing different types of disturbance is paramount to understanding cause-effect relations. The spectral, temporal, and spatial components that characterize disturbance types can be exploited for attribution. For example, the spectral response following fires contains a mixture of dead and burnt material and exposed soil [6264], while bark beetle-caused mortality differs by first showing needle discoloration and then loss $[54,65]$. By contrast, harvest typically results in an immediate increase in brightness and decrease in greenness [66]. While the focus of this review is on climate-induced vegetation disturbance, quantifying harvest can be essential to distinguish it from nonanthropogenic disturbances. These spectral responses can be used to discern different types of disturbance if they are spectrally distinct and included in a spectral library.

Disturbance types may have diagnostic temporal signatures (e.g., Figure S3 in the supplementary material online). Examination of temporal sequences of spectral indices has been effective at characterizing disturbance 
events, such as logging, fire, and insect outbreaks $[67,68]$. The advantage of analyzing multiple images is that a spectral record can be extracted to characterize the magnitude and direction of disturbance events [60] rather than seeking only the contrast between features from a single date. As computational and processing methods are automated, such temporal signatures will become increasingly accessible for attribution of disturbance events [69].

Different agents of change may also leave characteristic spatial signatures. For example, microbursts associated with squall lines or hurricanes [70] may leave a directional pattern (Figure 2C). Disturbance can increase fragmentation, where forested habitat is reduced into an increasing number of smaller, more isolated, patches [71]. As a result, the spatial patterns observed on imagery before, during, and after disturbance events can be used to attribute disturbance type. Natural disturbances often result in patches with different degrees of edge effect compared with harvesting [71-75]. Insect infestation causes greater numbers of patches, larger patch areas, increased forest patch shape complexity, reduced forest patch size, increased forest patch isolation, and increased edge density (e.g., Figure S4 in the supplementary material online [74]). Thus, spatial patterns of disturbances can be informative to attribute the cause of the disturbance, although approaches such as these have yet to be implemented in a more automated and comprehensive fashion at regional scales with multiple types of disturbance. Ultimately, successful classification hinges on not only the remotesensing tool, but also understanding of the underlying ecological processes. Unlike the detection phase, the attribution phase moves increasingly toward characterizing the temporal and spatial context, and away from the physics of detecting changes in the electromagnetic properties of the system.

\section{Disturbance causality}

Once disturbances have been detected and classified, the underlying cause of the disturbance is the penultimate stage in the global disturbance-monitoring scheme (Figure 1A). Wildfire and insect outbreaks demonstrate unique challenges to quantifying causation. Causative fire indices are used to predict fire risk and simulate fire behavior based on weather and fuel moisture. Combining these variables with fuel information estimated from remote sensing [76] allows determination of wildfire as the cause of disturbance [77-79]. Establishing disturbance causality allows not only for the monitoring of disturbance causation, but also projections in the future [80].

In the case of insect- and pathogen-induced mortality, causation is primarily limited to detecting early stages of infestation [81], investigating weather patterns in the lead up to outbreaks [82], using species distribution models driven by climate variables and host species distribution [83,84]. It may be aided by monitoring of trends in height or biomass production to understand the role of stand age and tree vigor on susceptibility. These models can be used in an inverse approach to determine the likelihood that a disturbance was driven by insect or pathogen outbreaks, and the underlying conditions that supported the outbreak.
Physiological, population, and agent-based models that simulate insect and pathogen demography are valuable to determine causation [85-90]. High-quality observations of dispersion kernels and transmission rates are needed to validate these models [91], and should be a continuing area of remote sensing research [92].

Quantification of the timing and severity of a disturbance can be critical to understanding the underlying mechanisms. A time series of tree mortality caused by a mountain pine beetle outbreak derived from Landsat imagery highlights this point (Figure S5 in the supplementary material online [87]). Warming and drought facilitated increases in beetle populations in 2001-2002 $[82,87,93]$. Drought relief in later years did not result in declines in tree mortality because beetles kill healthy trees when the population achieves outbreak proportions $[18,94]$. In addition to analyzing biotic and climatic disturbance interactions, remote-sensing products can be used to assess the role of climatic [95] and edaphic features [96] on tree mortality. These studies relating vegetation mortality to climate and edaphic factors are particularly relevant to land managers.

Ascribing causality moves the interpretation of disturbance even further from the source remote-sensing observations. As the examples above illustrate, disentangling multiple possible causes cannot be achieved without fundamental understanding of the ecological processes at play.

\section{Disturbance effects and consequences}

Disturbance consequences are the last step in our proposed framework (Figure 1). There are numerous ecosystem services impacted by disturbances [97]. Transfer of vegetation biomass from live to dead pools, for instance, shifts ecosystem energy loss from transpiration to direct radiative heat loss that causes warming, while also shifting albedo to promote cooling [98]. For example, large beetle-killed areas were shown through MODIS evapotranspiration and surface temperature to have warmed the atmosphere via greater radiative heat loss [99,100]. More long-lasting climate impacts are derived from the transfer of carbon to instable, dead pools that more readily decay, which can be estimated using remote sensing-based models [101,102]. Integrating remotely sensed observations of disturbance and their effects into (validated) ecosystem models is critical to understand the role of vegetation disturbance in ecological systems (e.g., [103]).

Fusion of model results with remote-sensing data is an effective approach to constrain estimates of the consequences of disturbances. Model-data fusion enhances accuracy of the interpretation of both the remotely sensed products and the models (e.g., [104]) and offers promise to improve parameter estimation [105]. We provide a detailed example using the Ecosystem Demography-Forest Reflectance and Transmittance model (ED-FRT), which is a new fusion of a forest ecosystem dynamics and a radiative transfer model that exchange information estimate mortality at subpixel resolution (Figure 4). ED-FRT simulates forest growth and mortality over time for regions that have been prescreened for tree mortality events using an appropriate detection method (e.g., [106]). Spectral reflectance 


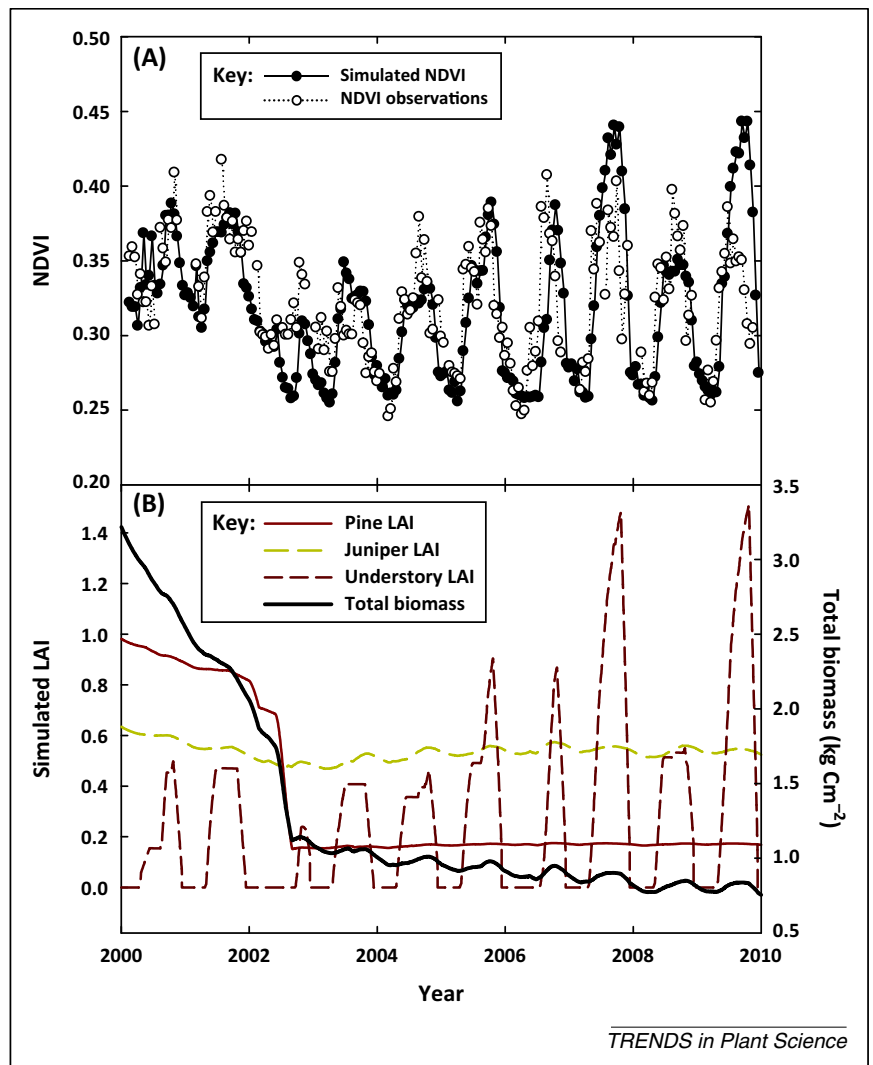

Figure 4. Model-data fusion as a futuristic approach to quantifying disturbances and their consequences. (A) Moderate Resolution Imaging Spectrometer (MODIS) observations and modeled Normalized Difference Vegetation Index (NDVI) for the field site shown in Figure 3, where extensive pine mortality occurred during drought in 2002-2003. Juniper trees survived, and the understory grasses and forbs increased their leaf area shortly thereafter. (B) Inverting the model so that NDVI is a constraint on the simulation, plus knowledge of pre-existing vegetation, allows accurate prediction of the composition dynamics of the dominan vegetation types at the site (compare the lower panel to direct observations in Figure 3) as well as the carbon consequence of the mortality event, a significant loss of live biomass. Abbreviation: LAI, Leaf Area Index.

and site data are collected for each disturbed pixel and used by ED to simulate separate tree cohorts (e.g., [107]). Once ED has produced the potential vegetation for each pixel, the spectral reflectance of the canopy is approximated by FRT. The resulting model output is a series of likely forest structures, each with distinct spectral signatures. By constraining the model output to that which best fits the spectral observations (Figure 4A), the most likely combination of forest dynamics is estimated (Figure $4 \mathrm{~B}$ ). In Figure 4, constraining the simulated spectral output against MODIS observations of NDVI resulted in a single ED output that matched observed vegetation dynamics with high precision (compare Figure 3 and Figure 4, which are the same site). We propose that, while existing remotesensing models (e.g., MODIS products) are valuable, additional information is likely to be gleaned from the fusion of process models with the remote-sensing data (e.g., Figure 4).

\section{Concluding remarks and path forward}

Ecologists have a long tradition of applying new technologies to discern natural patterns that were once unquantifiable. The technical opportunity (Figures 2-4, and
Figures S1-5 in the supplementary material online) and scientific need to apply remote-sensing science to disturbances is greater than ever because of the threat of increasing climate impacts. Figure 1 provides a framework from which we can conduct hypotheses tests, such as that of increasing disturbance rates in response to warming temperatures.

A consistent point of this review is the essential role that understanding ecological processes has when interpreting remotely sensed imagery of disturbance. Methods for detection through to understanding consequences must be tested more broadly than in the specific case studies presented here. Region-specific tests such as those shown in Figures 2-4 and in Figures S1-5 in the supplementary material online are promising, but without testing in disparate regions, their global applicability is limited. One advance that would facilitate testing of remote-sensing techniques is a global plot network that provides a benchmark map for remote-sensing disturbance estimates. Inventory networks such as Forest Geo, RAINFOR, and Forest Inventory and Analysis provide options for such a benchmarking network.

In the absence of ground data sets, further work using microwave and LIDAR or high-resolution ( 1-m) optical estimates for ground-truthing are valuable. Disturbances appear to be occurring at an increasing rate and severity that will result in novel disturbance regimes in locations where such disturbances have not occurred in recent history. As a result, it is critical for remote-sensing methods to be applied using a holistic framework, and validated to ensure the predictions are accurate. For example, broad-scale assessments of remotely sensed biomass (e.g., [108,109]) coupled with disturbance detection (e.g., [29,110]) have the potential to greatly inform the biomass consequences of disturbances. Accurate, repeatable, and transparent global monitoring of forest cover and disturbance is also an essential component of Reducing Emissions from Deforestation and Forest Degradation + (REDD+) policy. Currently, each country conducts their own forest-cover accounting, which leads to inconsistent and sometimes inaccurate information, thereby reducing willingness to invest in forest carbon credits. The forest disturbance monitoring approach introduced here is an important advance in providing the technical ability to fulfill these policy goals.

Remote-sensing science is on the verge of offering new insights into, and understanding of, the extent, type, and cause of disturbances worldwide. We hope that the eventual adoption of our framework, or a variant thereof, will lead to the greatest knowledge gains. Methods for the detection, classification, causation, and quantification of consequences of disturbances have been established. We make three recommendations regarding the implementation of a global disturbance monitoring system: (i) the technology must be sufficiently accurate to detect a range of disturbances and distinguish the type; (ii) a way must be found to integrate fine-scale analysis with global coverage; and (iii) ecological principles must be incorporated to understand the reason and consequences of observed patterns and to predict future trends. Detection, attribution, causation, and determining consequences of disturbances can and should all be achievable now at the global scale, 
provided it is informed by ecology. With this information in hand, major fundamental and applied gains are likely, with benefits to scientists, policymakers, and land managers.

\section{Acknowledgments}

This manuscript resulted from a workshop supported by Los Alamos National Laboratory's Interplanetary Geophysics and Planetary Physics (IGPP) program with additional support from the EU project EUFORINNO.

\section{Appendix A. Supplementary data}

Supplementary data associated with this article can be found, in the online version, at http://dx.doi.org/10.1016/j.tplants.2014.10.008.

\section{References}

1 Breshears, D.D. et al. (2005) Regional vegetation die-off in response to global-change-type drought. Proc. Natl. Acad. Sci. U.S.A. 102, 15144-15148

2 Van Mantgem, P.J. et al. (2009) Widespread increase of tree mortality rates in the western United States. Science 323, 521-524

3 Phillips, O.L. et al. (2009) Drought sensitivity of the Amazon rainforest. Science 323, 1344-1347

4 Carnicer, J. et al. (2011) Widespread crown condition decline, food web disruption, and amplified tree mortality with increased climate change-type drought. Proc. Natl. Acad. Sci. U.S.A. 108, 1474-1478

5 Peng, C.H. et al. (2011) A drought-induced pervasive increase in tree mortality across Canada's boreal forests. Nat. Clim. Change 1, $467-471$

6 McDowell, N.G. et al. (2008) Mechanisms of plant survival and mortality during drought: why do some plants survive while others succumb? New Phytol. 178, 719-739

7 Allen, C.D. et al. (2010) A global overview of drought and heat-induced tree mortality reveals emerging climate change risks for forests. Forest Ecol. Manag. 259, 660-684

8 Hicke, J.A. et al. (2012) Effects of biotic disturbances on forest carbon cycling in the United States and Canada. Global Change Biol. 18, 7-34

9 Edburg, S.L. et al. (2012) Cascading ecosystem impacts of bark beetlecaused tree mortality. Front. Ecol. Environ. 10, 416-424

10 Reichstein, M. et al. (2013) Climate extremes and the carbon cycle. Nature 500, 287-295

11 Goetz, S.J. et al. (2012) Observations and assessment of forest carbon dynamics following disturbance in North America. J. Geophys. Res. Published online June 9, 2012, http://dx.doi.org/10.1029/2011jg001733

12 Bar Massada, A. et al. (2013) Wildfire ignition distribution modeling: a comparative study in the Huron-Manistee National Forest, Michigan, USA. Int. J. Wildl. Fire 22, 174-183

13 Allen, C.D. et al. (2002) Ecological restoration of southwestern ponderosa pine ecosystems: a broad perspective. Ecol. Appl. 12, 1418-1433

14 Delbart, N. et al. (2010) Mortality as a key driver of the spatial distribution of aboveground biomass in Amazonian forests: results from a Dynamic Vegetation Model. Biogeosciences 7, 3027-3039

15 Fisher, R. et al. (2010) Assessing uncertainties in a second-generation dynamic vegetation model due to ecological scale limitations. New Phytol. 187, 666-681

16 Van der Molen, M.K. et al. (2011) Drought and ecosystem carbon cycling. Agric. Forest Meteorol. 151, 765-773

17 McDowell, N.G. et al. (2013) Evaluating theories of drought-induced vegetation mortality using a multi-model-experiment framework. New Phytol. 200, 304-321

18 McDowell, N.G. et al. (2011) Interdependence of mechanisms underlying climate-driven vegetation mortality. Trends Ecol. Evol. $26,523-532$

19 Romme, W.H. et al. (1998) Are large, infrequent disturbances qualitatively different from small, frequent disturbances? Ecosystems $1,524-534$

20 Potter, C. et al. (2003) Continental-scale comparisons of terrestrial carbon sinks estimated from satellite data and ecosystem modeling 1982-1998. Global Planetary Change 39, 201-213
21 Fraser, R.H. et al. (2005) A method for detecting large-scale forest cover change using coarse spatial resolution imagery. Remote Sens. Environ. 95, 414-427

22 Coops, N.C. et al. (2006) Identifying and describing forest disturbance and spatial pattern: data selection issues and methodological implications. In Forest Disturbance and Spatial Pattern: Remote Sensing and GIS Approaches (Wulder, M. and Franklin, S., eds), pp. 33-60, Taylor \& Francis

23 Dale, V.H. et al. (2001) Climate change and forest disturbances. Bioscience 51, 723-734

24 Turner, M.G. (2010) Disturbance and landscape dynamics in a changing world. Ecology 91, 2833-2849

25 Cohen, W.B. and Goward, S.N. (2004) Landsat's role in ecological applications of remote sensing. BioScience 54, 535-545

26 Mildrexler, D.J. et al. (2007) A new satellite-based methodology for continental-scale disturbance detection. Ecol. Appl. 17, 235-250

27 Mildrexler, D.J. et al. (2009) Testing a MODIS global disturbance index across North America. Remote Sens. Environ. 113, 2103-2117

28 Cohen, W.B. et al. (2002) Characterizing 23 years (1972-95) of stand replacement disturbance in western Oregon forests with Landsat imagery. Ecosystems 5, 122-137

29 Hansen, M.C. et al. (2013) High-resolution global maps of 21stcentury forest cover change. Science $342,850-853$

30 Toomey, M. et al. (2013) Long term, high spatial resolution carbon balance monitoring of the Amazonian frontier: pre- and postdisturbance carbon emissions and uptake. J. Geophys. Res. Biogeosci. 118, 400-411

31 Asner, G.P. (2001) Cloud cover in Landsat observations of the Brazilian Amazon. Int. J. Remote Sens. 22, 3855-3862

32 Garrity, S.R. et al. (2013) Quantifying drought-induced tree mortality in a piñon-juniper woodland using multitemporal high spatial resolution satellite imagery. Remote Sens. Environ. 129, 54-65

33 Skurikhin, A. et al. (2013) Automated tree crown detection and size estimation using multi-scale analysis of high resolution satellite imagery. Remote Sens. Lett. 4, 465-474

34 Goetz, S.J.et al. (2010) Synergistic use of spaceborne lidar and optical imagery for assessing forest disturbance: an Alaska case study. $J$. Geophys. Res. Biogeosci. Published online January 14, 2010, http:// dx.doi.org/10.1029/2008JG000898

35 Saatchi, S.S. et al. (2013) Persistent effects of a severe drought on Amazonian forest canopy. Proc. Natl. Acad. Sci. U.S.A. 110, 565-570

$36 \mathrm{Yu}, \mathrm{X} . \mathrm{W}$. et al. (2004) Automatic detection of harvested trees and determination of forest growth using airborne laser scanning. Remote Sens. Environ. 90, 451-462

37 Moran, M.S. et al. (1994) Estimating crop water deficit using the relation between surface-air temperature and spectral vegetation index. Remote Sens. Environ. 49, 246-263

38 Leuzinger, S. and Korner, C. (2007) tree species diversity affects canopy leaf temperatures in mature forest. Agric. Forest Meteorol. $146,29-37$

39 Ustin, S.L. and Gannon, J.A. (2010) Remote sensing of plant functional types. New Phytol. 186, 795-816

40 Kauth, R.J. and Thomas, G.S. (1976) The tasseled cap- a graphic description of spectral-temporal development of agricultural crops as seen by LANDSAT. LARS Symposia Paper 159

41 Crist, E.P. and Cicone, R.C. (1984) Application of the tasseled cap concept to simulated Thematic Mapper data. Photogramm. Eng. Remote Sens. 50, 343-352

42 Crist, E.P. and Kauth, R.J. (1986) The tasseled cap de-mystified. Photogramm. Eng. Remote Sens. 52, 81-86

43 Brown, J.F. et al. (2008) The vegetation drought response index (VegDRI): a new integrated approach for monitoring drought stress in vegetation. GISci. Remote Sens. 45, 16-46

44 Kogan, F.N. (1997) Global drought watch from space. Bull. Am. Meteorol. Soc. 78, 621-636

45 Borak, J.S. et al. (2000) The use of temporal metrics for land cover change detection at coarse spatial scales. Int. J. Remote Sens. 21, $1415-1432$

46 Sellers, P.J. (1985) Canopy reflectance, photosynthesis and transpiration. Int. J. Remote Sens. 6, 1335-1372

47 Asner, G.P. et al. (2012) High-resolution mapping of forest carbon stocks in the Colombian Amazon. Biogeosci. Discuss. 9, 3 
48 Zhou, L. et al. (2014) Widespread decline of Congo rainforest greenness in the past decade. Nature 509, 86-90

49 Turner, M.G. (1989) Landscape ecology: the effect of pattern on process. Annu. Rev. Ecol. Syst. 20, 171-197

50 Meddens, A.J.H. et al. (2013) Evaluating methods to detect bark beetle-caused tree mortality using single-date and multi-date Landsat imagery. Remote Sens. Environ. 132, 49-58

51 Negrón-Juárez, R.I. et al. (2010) Widespread Amazon forest tree mortality from a single cross-basin squall line event. Geophys. Res. Lett. 37, L16701

52 Negrón-Juárez, R.I. et al. (2011) Detection of subpixel treefall gaps with Landsat imagery in Central Amazon forests. Remote Sens. Environ. 115, 3322-3328

53 Wulder, M.A. et al. (2006) Surveying mountain pine beetle damage of forests: a review of remote sensing opportunities. Forest Ecol. Manag. $221,27-41$

54 Wulder, M.A. et al. (2008) Multi-temporal analysis of high spatial resolution imagery for disturbance monitoring. Remote Sens. Environ. 112, 2729-2740

55 Kennedy, R.E. et al. (2014) Bringing an ecological view of change to Landsat-based remote sensing. Front. Ecol. Environ. 12, 339-346

56 Worrall, J.J. et al. (2013) Recent declines of Populus tremuloides in North America linked to climate. Forest Ecol. Manag. 299, 35-51

57 Adams, J.B. et al. (1995) Classification of multispectral images based on fractions of endmembers: application to land-cover change in the Brazilian Amazon. Remote Sens. Environ. 52, 137-154

58 Huang, C. and Anderegg, W.R.L. (2012) Large drought-induced aboveground live biomass losses in southern Rocky Mountain aspen forests. Global Change Biol. 18, 1016-1027

59 Williams, A.P. et al. (2013) Temperature as a potent driver of regional forest drought stress and tree mortality. Nat. Clim. Change 3, 292-297

60 Goodwin, N.R. et al. (2008) Estimation of insect infestation dynamics using a temporal sequence of Landsat data. Remote Sens. Environ. $112,3680-3689$

61 Beck, P.S.A. et al. (2011) Changes in forest productivity across Alaska consistent with biome shift. Ecol. Lett. 14, 373-379

62 Meigs, G.W. et al. (2011) A Landsat time series approach to characterize bark beetle and defoliator impacts on tree mortality and surface fuels in conifer forests. Remote Sens. Environ. 115, 3707-3718

63 Kennedy, R.E. et al. (2012) Spatial and temporal patterns of forest disturbance and regrowth within the area of the Northwest Forest Plan. Remote Sens. Environ. 122, 117-133

$64 \mathrm{Zhu}$, Z. et al. (2012) Continuous monitoring of forest disturbance using all available Landsat imagery. Remote Sens. Environ. 122, 75-91

65 Giglio, L. et al. (2003) An enhanced contextual fire detection algorithm for MODIS. Remote Sens. Environ. 87, 273-282

66 Cohen, W.B. et al. (1998) An efficient and accurate method for mapping forest clearcuts in the Pacific Northwest using Landsat imagery. Photogramm. Eng. Remote Sens. 64, 293-300

67 Coppin, P. et al. (2004) Digital change detection methods in ecosystem monitoring: a review. Int. J. Remote Sens. 25, 1565-1596

68 Kennedy, R.E. et al. (2007) Trajectory-based change detection for automated characterization of forest disturbance dynamics. Remote Sens. Environ. 110, 370-386

69 Wulder, M.A. et al. (2012) Opening the archive: how free data has enabled the science and monitoring promise of Landsat. Remote Sens. Environ. 122, 2-10

70 Chambers, J.Q. et al. (2007) Hurricane Katrina's carbon footprint on Gulf Coast forests. Science 318, 1107

71 Wilcove, D.S. et al. (1986) Habitat fragmentation in the temperate zone. Conserv. Biol. 6, 237-256

72 Tinker, D.B. et al. (1998) Watershed analysis of forest fragmentation by clearcuts and roads in a Wyoming forest. Landscape Ecol. 13, 149-165

73 Gillanders, S.N. et al. (2008) Application of Landsat satellite imagery to monitor land-cover changes at the Athabasca Oil Sands, Alberta, Canada. Can. Geogr. 52, 466-485

74 Coops, N.C. et al. (2010) Assessing changes in forest fragmentation following infestation using time series Landsat imagery. Forest Ecol. Manag. 259, 2355-2365

75 Antonova, N. et al. (2013) Landsat-based Monitoring of Landscape Dynamics in the North Cascades National Park Service Complex: 1985-2009, Natural Resource Data Series
76 Arroyo, L.A. et al. (2008) Fire models and methods to map fuel types: the role of remote sensing. Forest Ecol. Manag. 256, 1239-1252

77 Prins, E.M. et al. (1998) An overview of GOES-8 diurnal fire and smoke results for SCAR-B and 1995 fire season in South America. J. Geophys. Res. Atmos. 103, 31821-31835

78 Koetz, B. et al. (2008) Multi-source land cover classification for forest fire management based on imaging spectrometry and LiDAR data. Forest Ecol. Manag. 256, 263-271

79 Amraoui, M. et al. (2013) Fire activity over Mediterranean Europe based on information from Meteosat-8. Forest Ecol. Manag. 294, 62-75

80 Flannigan, M. et al. (2013) Global wildland fire season severity in the 21st century. Forest Ecol. Manag. 294, 54-61

81 Wulder, M.A. et al. (2008) Monitoring tree-level insect population dynamics with multi-scale and multi-source remote sensing. J. Spat. Sci. 53, 49-61

82 Creeden, E.P. et al. (2014) Climate, weather, and recent mountain pine beetle outbreaks in the western United States. Forest Ecol. Manag. 312, 239-251

83 Wang, X.Y. et al. (2010) Predicting potential distribution of chestnut phylloxerid (Hemiptera: Phylloxeridae) based on GARP and Maxent ecological niche models. J. Appl. Entomol. 134, 45-54

84 Evangelista, P.H. et al. (2011) Assessing forest vulnerability and the potential distribution of pine beetles under current and future climate scenarios in the Interior West of the US. Forest Ecol. Manag. 262, $307-316$

85 Jönsson, A.M. et al. (2007) Impact of climate change on the population dynamics of Ips typographus in southern Sweden. Agric. Forest Meteorol. 146, 70-81

86 Meentemeyer, R.K. et al. (2011) Epidemiological modeling of invasion in heterogeneous landscapes: spread of sudden oak death in California (1990-2030). Ecosphere 2, art17

87 Boyd, I.L. et al. (2013) The consequence of tree pests and diseases for ecosystem services. Science 342, 1235773

88 Økland, B. and Bjørnstad, O.N. (2006) A resource-depletion model of forest insect outbreaks. Ecology 87, 283-290

89 Fettig, C.J. et al. (2007) The effectiveness of vegetation management practices for prevention and control of bark beetle infestations in coniferous forests of the western and southern United States. Forest Ecol. Manag. 238, 24-53

90 Régnière, J. and Bentz, B. (2007) Modeling cold tolerance in the mountain pine beetle, Dendroctonus ponderosae. J. Insect Physiol. $53,559-572$

91 Powers, J.S. et al. (1999) Plant-pest interactions in time and space: a Douglas-fir bark beetle outbreak as a case study. Landscape Ecol. 14, 105-120

92 Meddens, A.J.H. and Hicke, J.A. (2014) Spatial and temporal patterns of tree mortality caused by a mountain pine beetle outbreak in Colorado, USA. Forest Ecol. Manag. 322, 78-88

93 Chapman, T.B. et al. (2012) Spatiotemporal patterns of mountain pine beetle activity in the southern Rocky Mountains. Ecology 93, 2175-2185

94 Raffa, K.F. et al. (2008) Cross-scale drivers of natural disturbances prone to anthropogenic amplification: the dynamics of bark beetle eruptions. Bioscience 58, 501-517

95 Clifford, M.J.et al. (2013) Precipitation thresholds and drought-induced tree die-off: insights from patterns of Pinus edulis mortality along an environmental stress gradient. New Phytol. 200, 413-421

96 Walter, J.A. and Platt, R.V. (2013) Multi-temporal analysis reveals that predictors of mountain pine beetle infestation change during outbreak cycles. Forest Ecol. Manag. 302, 308-318

97 Anderegg, W.R.L. et al. (2013) Consequences of widespread tree mortality triggered by drought and temperature stress. Nat. Clim. Change 3, 30-36

98 Lee, X. et al. (2011) Observed increase in local cooling effect of deforestation at higher latitudes. Nature 479, 384-387

99 Maness, H. et al. (2013) Summertime climate response to mountain pine beetle disturbance in British Columbia. Nat. Geosci. 6, 65-70

100 Bright, B.C. et al. (2013) Effects of bark beetle-caused tree mortality on biogeochemical and biogeophysical MODIS products. J. Geophys. Res. Biogeosci. Published online July 1, 2013, http://dx.doi.org/10. 1002/jgrg.20078

101 Beck, P.S.A. et al. (2011) The impacts and implications of an intensifying fire regime on Alaskan boreal forest composition and albedo. Global Change Biol. 17, 2853-2866 
102 Bright, B.C. et al. (2012) Estimating aboveground carbon stocks of a forest affected by mountain pine beetle in Idaho using lidar and multispectral imagery. Remote Sens. Environ. 124, 270-281

103 Verma, M.A. et al. (2013) Remote sensing of annual terrestrial gross primary productivity from MODIS: an assessment using the FLUXNET La Thuile dataset. Biogeosci. Discuss. 10, 11627-11669

104 Peng, C.H. et al. (2011) Integrating models with data in ecology and palaeoecology: advances towards a model-data fusion approach. Ecol. Lett. 14, 522-536

105 Liang, X.Z. et al. (2007) Regional climate model simulation of USMexico summer precipitation using the optimal ensemble of two cumulus parameterizations. J. Clim. 20, 5201-5207

106 Kennedy, R.E. et al. (2009) Remote sensing change detection tools for natural resource managers: Understanding concepts and tradeoffs in the design of landscape monitoring projects. Remote Sens. Environ. $113,1382-1396$

107 Moorcroft, P.R. et al. (2001) A method for scaling vegetation dynamics: the ecosystem demography model (ED). Ecol. Monogr. $71,557-586$

108 Saatchi, S. et al. (2011) Benchmark map of forest carbon stocks in tropical regions across three continents. Proc. Natl. Acad. Sci. U.S.A. 108, 9899-9904

109 Baccini, A. et al. (2012) Estimated carbon dioxide emissions from tropical deforestation improved by carbon-density maps. Nat. Clim. Change 2, 182-185

110 Hicke, J.A. et al. (2013) Carbon stocks of trees killed by bark beetles and wildfire in the western United States. Environ. Res. Lett. 8, 035032 